\title{
Demanda de informação pelo setor industrial: dois estudos no intervalo de 25 anos
}

\author{
Vania M. R. Hermes de Araujo \\ Isa Maria Freire \\ Teresa Cristina M. Mendes
}

\section{Resumo \\ Os estudos sobre a demanda de informação dos usuários do setor produtivo industrial tornam-se cada vez mais necessários, à medida que a informação se estabelece como fator/insumo de produção. Neste trabalho, são analisados, comparativamente, dois estudos em nível nacional, separados por um intervalo de tempo de 25 anos. Neles, pode-se observar semelhanças e diferenças, sendo possivel distinguir quais os tipos de informação mais relevantes para o setor industrial, nas respectivas etapas históricas. Ambos os estudos foram promovidos mediante cooperação entre o setor público e o setor privado, por suas entidades representativas.}

\section{Palavras-chave}

Demanda de informação; Informação industrial; Setor produtivo.

\section{A PRODUÇÃO SOCIAL DA INFORMAÇÃO}

Na sociedade industrial, a ciência tornou-se a principal forma de conhecimento sobre o mundo, formando a base para o desenvolvimento de uma tecnologia que transformou os meios e as relações de produção. E sendo resultado de processos em uma dada formação econômica e cultural, as atividades científicas e tecnológicas se inserem nas estruturas sociais, atendem a necessidades da própria organização da sociedade e fazem parte do sistema de trocas simbólicas e materiais ${ }^{1}$.

As sociedades que antecederam a sociedade industrial foram sociedades em que a necessidade de conhecimento excedia a oferta, e os custos de produção da informação eram altos. A situação atual é que a oferta excede a demanda: não se trata apenas de organizar e fazer circular na sociedade o conhecimento, mas, especialmente, de fazer chegar a um receptor as informações que representem possibilidades de acesso ao conhecimento disponível e viabilizar seu uso. Nesse sentido, o crescimento da produção científica e tecnológica está na gênese do fenômeno da "explosão da informação", que representa a expansão e diversificação das fontes e canais de comunicação do conhecimento para os inúmeros grupos que dele necessitam em suas respectivas atividades profissionais².

Nesse contexto, o principal fator de mudança e criação de riquezas, dirigindo a produtividade dos meios e processos produtivos, tem sido o progresso tecnológico, através da inovação ou aplicação do conhecimento científico com sucesso econômico ${ }^{3}$. Na sociedade atual, o sucesso na produção tem sido caracterizado pela busca de informação, pela comunicação com fontes de conhecimento relevantes, pela capacidade de absorção de tecnologias nas unidades produtivas e, especialmente, pela capacidade para produção e avaliação de informações ${ }^{4}$.

O potencial de qualquer grupo produtor de bens e serviços para receber informação pode ser considerado como uma função do seu meio ambiente, envolvendo fatores econômicos, políticos e culturais. Barreiras ao fluxo de pessoas e de informação entre o grupo e seu meio ambiente certamente limitam o atendimento das necessidades de informação limitando, também, o potencial de inovação dos diversos grupos em ação na sociedade ${ }^{5}$.

Por sua vez, são as características de cada grupo, incluindo seus recursos humanos e materiais, padrões de comunicação e de tomada de decisão que irão determinar a realização do seu potencial de inovação, seja para o desenvolvimento de novos produtos ou processos, seja na adoção de novas metodologias para gestão dos recursos disponíveis. É assim que, ao investir no conhecimento científico e tecnológico, os grupos produtores de bens e serviços estão desenvolvendo sua capacidade de "reconhecer, assimilar e explorar informações disponíveis"6. Pois devido à complexidade dos processos produtivos na sociedade contemporânea, somente: 
"(...) [um] arranjo de várias fontes de idéias e informações, tanto internas quanto externas, pode ser considerada a forma mais completa de as firmas se capacitarem para enfrentar mudanças tecnológicas.... estudos empíricos demonstram que se torna cada vez mais usual o estabelecimento de relações interativas de troca de informações e de conhecimento..."7.

Ao longo do processo histórico de formação da sociedade industrial, a dinâmica da produção científica e tecnológica desenvolveu seu próprio sistema de comunicação, de modo a promover a circulação e troca de conhecimentos. Nesse contexto, uma área de atividade emergiu no campo científico ${ }^{8}$,

"(...) não por causa de um fenômeno específico que existia antes e que veio a se tornar seu objeto de estudo - mas por causa da necessidade de abordar um problema que mudara completamente sua relevância para a sociedade" 9 .

Na visão dos autores, o propósito desse campo científico é definido por sua "responsabilidade social" e suas atividades devem ser dirigidas no sentido de "facilitar a transmissão de conhecimento para aqueles que dele necessitam"10. Adotando essa perspectiva, BeIkin e Robertson ${ }^{11}$ colocam que, para estudar o fenômeno da informação, é necessário considerá-lo como um processo de comunicação social, que contextualiza informação, emissor e receptor numa sociedade que valoriza o conhecimento científico e tecnológico. Esse conhecimento tem se transformado historicamente, mas sempre no sentido de representar uma informação que apóia uma ação dentro de uma situação específica, diminuindo a incerteza sobre o comportamento do sistema em sua interação com o meio ambiente ${ }^{12}$. Nesse sentido, o estudo dos canais de comunicação e mecanismos de transmissão entre fontes do conhecimento e seus usuários potenciais na sociedade tornou-se uma questão de interesse para a ciência da informação ${ }^{13}$. Por sua vez, a relevância das atividades de informação para o desenvolvimento das forças produtivas na sociedade contemporânea decorre do papel dos profissionais da informação como facilitadores da comunicação entre usuários que necessitam de conhecimento para ação ${ }^{14}$ e fontes que produzem, organizam e distribuem informação, ou dispõem de mecanismos de acesso a esse recurso.

Esse papel de facilitador se realiza, concretamente, através da interação com inúmeros outros produtores, mecanismos e canais de circulação do conhecimento, criando-se novas oportunidades para transferência da informação para seus usuários na sociedade, tanto nas atividades de ciência e tecnologia, quanto no setor produtivo. Para apoiar sua ação na sociedade, os profissionais da informação necessitam conhecer os receptores da informação, seus usuários reais (os que já se utilizam das fontes, por meio de serviços e produtos de informação) e potenciais (que podem vir a buscar informação nas fontes disponíveis).

Por um lado, enquanto produtores, os profissionais da informação precisam conhecer o mercado ao qual destinam seus produtos e serviços, para identificar os formatos e conteúdos mais adequados às estruturas cognitivo-culturais dos diversos grupos que usam informação como insumo no processo de produção industrial, inclusive as atividades científicas e tecnológicas.

Por outro, enquanto facilitadores da comunicação, necessitam desenvolver mecanismos de aproximação com seus usuários, de modo a receber indicações sobre quais canais e mecanismos seriam mais adequados ao atendimento das demandas de cada grupo, seja para tomada de decisão no gerenciamento dos recursos nas empresas, para agregar novos conhecimentos a indivíduos e grupos sociais, ou para inúmeras outras finalidades.

Os estudos necessários para apoiar a ação dos profissionais da informação têm sido tradicionalmente denominados, na ciência da informação, "estudos de usuários" e são definidos por Figueiredo como:

"(...) investigações que se fazem para saber o de que os indivíduos precisam em matéria de informação, ou então, para saber se as necessidades de informação por parte dos usuários (...) estão sendo satisfeitas de maneira adequada. (...) Através destes estudos, verifica-se por que, como e para quais fins os indivíduos usam informação, e quais os fatores que afetam tal uso. Os usuários são assim encorajados a tornar as suas necessidades conhecidas..."15.

Embora os estudos de usuários tenham, tradicionalmente, enfocado os indivíduos e grupos envolvidos na produção do conhecimento científico e tecnológico, abordando seus padrões característicos de comunicação com uma ou várias fontes de informação, o foco no usuário do setor produtivo se ampliou à medida que cresciam tanto a oferta de produtos e serviços de informação, quanto a demanda das indústrias por informação que represente acesso ao "conhecimento para ação"16.

Em decorrência, reconhece-se cada vez mais a informação (e sua efetiva comunicação) como um dos recursos mais importantes para a produção de bens e serviços. Na sua pesquisa com usuários da informação no setor produtivo, Mualem encontrou um percentual significativo de empresas que, ao avaliar os fatores que influenciam o desempenho de uma indústria, atribuiu o grau pleno à "disponibilidade de informação para a gerência" e grande à "disponibilidade de informação para o planejamento da empresa"17.

Recentemente, investigando as relações entre "a transferência de informação, o desenvolvimento tecnológico e a produção de conhecimento", Barreto também encontrou correlação positiva entre acesso e uso da informação e progresso técnico nas indústrias consultadas em vários municípios brasileiros, identificando a disponibilidade de informação como um dos fatores contextuais que condicionam a assimilação de novas tecnologias ${ }^{18}$.

\section{DEMANDA DE INFORMAÇÃO PELO SETOR PRODUTIVO}

A identificação das necessidades de informação do setor industrial apresenta-se como uma preocupação permanente das áreas/instituições envolvidas com a oferta de produtos/serviços de informação, à medida que o melhor conhecimento do mercado demandante permite melhor orientação dos recursos definidos para este fim. 
Uma avaliação da evolução destas necessidades, ao longo do tempo, poderia vir a representar um importante balizador do grau de aderência da oferta à demanda, posto que sinalizaria para as necessidades atendidas e para aquelas (ainda) não atendidas, assim como para a própria carência do setor industrial quanto à informação tecnológica.

A análise que se segue objetiva, portanto, traçar um quadro da evolução destas necessidades, a partir do confronto de dois estudos realizados para conhecer a demanda por informação pela indústria: o primeiro, realizado por Pompeu et alli', em 1971, e o segundo, realizado por CNI/Dampi e Senai/ Ciet $^{20}$, em 1996, com a colaboração do Sebrae.

O estudo de Pompeu et alli pode ser considerado a primeira tentativa bemsucedida de pesquisa nesta área no país e "(...) teve por objetivo orientar o Centro de Informações Tecnológicas (CIT), do Instituto Nacional de Tecnologia (INT), na escolha dos seus critérios de aquisição e disseminação de informação, mediante o conhecimento das necessidades de seus usuários e algumas de suas características principais" 21 .

A Pesquisa da CNI e do Senai "(...) partiu da necessidade de se conhecer a demanda por informação da indústria e de se identificar áreas nas quais os serviços e produtos de informação precisam ser aperfeiçoados, expandidos ou desenvolvidos"22. Surgida no âmbito da Subcomissão de Informação Tecnológica do PACTI ${ }^{23}$, sua motivação reproduz aquela de 25 anos atrás, do primeiro estudo, qual seja, a de conhecer a demanda da indústria para meIhor posicionar a oferta de produtos e serviços.

Embora o intervalo de tempo entre os dois estudos seja bastante significativo, curiosamente ambos guardam algumas semelhanças em seus resultados, conforme será visto adiante.

\section{ASPECTOS METODOLÓGICOS}

O estudo de Pompeu et alli partiu das respostas de 1302 empresas industriais, classificadas em 32 ramos industriais - em uma amostra selecionada de 5100 empresas, com mais de 25 operários, que receberam o questionário -, e de dados relativos às solicitações da indústria ao CIT de resumos de artigos técnicos publicados.

O questionário da pesquisa ateve-se somente a sete questões: três relativas ao fornecimento de artigos técnicos (áreas de interesse e serviços de tradução), três referentes a características da indústria no uso da informação (assinatura de revistas técnicas, solução de problemas e nível da assessoria técnica) e uma relativa ao contato na empresa.

As solicitações de resumos de artigos técnicos, por sua vez, foram classificadas em cinco categorias, visando a homogeneizar as informações com aquelas da pesquisa: processo de fabricação, matéria-prima, novos produtos, controle de qualidade e equipamentos ${ }^{24}$.

À pesquisa da CNI e do Senai, responderam 1990 empresas industriais, em uma amostra selecionada de $4.648 \mathrm{em}$ presas, estratificadas segundo o porte (micro, pequena, média e grande) e setores de atividade (11 setores).

O questionário, mais complexo, possuía 14 questões, sendo que 12 delas abordaram os seguintes aspectos:

- uso da informação tecnológica e caracterização da indústria (sete questões);

- demanda por área de atuação - compras, produção, vendas e gestão (quatro questões);

- demanda por produtos e serviços de informação (uma questão).

A análise que se segue excluiu o segmento de microempresas (até $19 \mathrm{em}$ pregados), abordado no estudo da CNI/ Dampi e Senai/Ciet, em uma tentativa de tornar mais comparáveis os universos investigados.

\section{ANÁLISE COMPARATIVA DOS RESULTADOS}

\section{a) Análise global}

Inicialmente, cabe ressaltar que o destaque de alguns pontos levantados no estudo de 1971 e sem correspondência na pesquisa de 1996, ao menos em termos de freqüência, pode ser atribuído a diferenças de metodologia ou de entendimento dos conceitos.

Este não parece ser o caso, todavia, de serviços de tradução, por exemplo. Analisando-se os resultados, percebese uma clara diferenciação na postura do setor industrial nos dois estudos: enquanto em 1971, 61,2\% das unidades pesquisadas declararam preferir receber os documentos traduzidos, na pesquisa de 1996, apenas $12,3 \%$ indicaram este serviço de informação como um dos principais que atenderiam meIhor às necessidades da empresa. Esta diferença poderia ser explicada, em princípio, pela própria qualificação exigida dos técnicos pelo mercado, atualmente mais rigorosa em comparação com o quadro de 25 anos atrás.

Quanto às similaridades, estas se iniciam pelas fontes de informação das empresas. Em ambos os estudos, é elevado o percentual de empresas industriais que têm nas publicações uma importante fonte. No estudo de 1971, $55,5 \%$ das indústrias responderam que assinam regularmente revistas nacionais e estrangeiras, enquanto $58,9 \%$ declararam, em 1996, dispor das publicações especializadas (revistas, boletins etc.) como uma das fontes de informação mais utilizadas.

Em termos de assuntos de maior interesse por parte da indústria, constatase novamente semelhança nas demandas. Partindo-se dos temas levantados pelo estudo de 1971, percebe-se que os mesmos também estão presentes como solicitações no estudo de 1996 , mediante uma tentativa de compatibilização dos conceitos entre os dois estudos. As tabelas 1 e 2 , a seguir, assim o demonstram: 


\section{b) Análise setorial}

Sob a abordagem setorial, também os estudos apresentam similaridades, embora com ressalvas a respeito da compatibilidade em termos de denominação dos setores. Para o estudo de 1971, "os setores onde a demanda de informação é mais significativa foram considerados aqueles em que a resposta aos questionários situou-se acima do valor médio de 24,16\%"25. Estes corresponderam a três setores, entre os 11 trabalhados: fabricação de têxteis $(29,80 \%)$, plásticos $(29,67 \%)$ e fabricação de alimentos (26,25\%).

Com relação ao estudo de 1996, a amostra setorial de pequenas, médias e grandes empresas teve, em alimentos/bebidas e têxtil/vestuário, o maior número de empresas, atrás apenas de metalurgia, minerais metálicos e não metálicos: 13,6\% e 12,7\% da amostra, respectivamente. O setor de borracha/ plástico, por sua vez, contribuiu com $7,5 \%$ das empresas selecionadas.

Pelo lado das diferenças, a abertura por setores reforça as conclusões da análise global para a questão da tradução, ou seja, todos estes setores atualmente têm, na tradução de documentos técnicos, um dos serviços menos demandados aos centros provedores de informação tecnológica, ao contrário do que ocorria há 25 anos, conforme tabela 3.

Quanto às fontes de informação, a evolução ao longo do tempo demonstra que as publicações especializadas continuam sendo uma importante referência para as atividades do setor industrial, qualquer que seja o setor, de acordo com o detalhamento (tabela 4).

Curiosamente, a ordem dos setores em termos de freqüência de respostas é a mesma para ambos os estudos, mesmo tendo decorrido um intervalo de tempo tão grande.

No que tange aos temas que mais interessam aos setores industriais, novamente há coerência entre os dois estudos, conforme pode ser observado nos gráficos a seguir, ainda que em ordem de importância a semelhança não seja tão significativa. Neste caso, buscou-se compatibilizar, ao máximo, os conceitos
TABELA 1

Análise comparativa das demandas efetivadas

\begin{tabular}{lclc}
\hline Estudo de 1971 & $\begin{array}{c}\text { \% de } \\
\text { Empresas* }\end{array}$ & \multicolumn{1}{c}{ Estudo de 1996 } & $\begin{array}{c}\% \text { de } \\
\text { Empresas }^{\star *}\end{array}$ \\
\hline Processos & 56,1 & $\begin{array}{l}\text { Processo de produção/ controle } \\
\text { de qualidade/gestão organizacional }\end{array}$ & 48,9 \\
Equipamentos & 50,6 & $\begin{array}{l}\text { Fornecedores de máquinas e } \\
\text { equipamentos }\end{array}$ & 39,7 \\
Controle de qualidade & 44,4 & $* * *$ & $* * *$ \\
Matéria-prima & 42,9 & $\begin{array}{l}\text { Fornecedores de matérias-primas } \\
\text { e insumos }\end{array}$ & 36,2 \\
\hline
\end{tabular}

* $\quad$ Corresponde ao percentual de pedidos de resumos de artigos técnicos sobre o que foi publicado.

** Corresponde ao percentual de empresas que buscaram informações nas instituições listadas no estudo.

*** Ressalta-se que o item referente a controle de qualidade está presente no 1ํitem listado para o estudo de 1996 - processo de produção/controle de qualidade/gestão organizacional.

TABELA 2

Análise comparativa das demandas potenciais

\begin{tabular}{|c|c|c|c|}
\hline Estudo de 1971 & $\begin{array}{c}\% \text { de } \\
\text { Empresas* }\end{array}$ & Estudo de 1996 & $\begin{array}{c}\% \text { de } \\
\text { Empresas }^{\star *}\end{array}$ \\
\hline Processos & 77,8 & $\begin{array}{l}\text { Tecnologias de processos/ } \\
\text { produtos/gestão }\end{array}$ & 53,1 \\
\hline Equipamentos & 72,2 & Máquinas/equipamentos & 52,0 \\
\hline Controle de qualidade & 66,6 & $\begin{array}{l}\text { Métodos e técnicas de } \\
\text { controle da qualidade }\end{array}$ & 58,0 \\
\hline Matéria-prima & 62,4 & Matérias-primas/insumos & 69,0 \\
\hline
\end{tabular}

* Corresponde ao percentual de empresas interessadas nos temas sugeridos pela pesquisa. ** idem.

TABELA 3

Análise comparativa das necessidades de tradução por setores

\begin{tabular}{lclc}
\hline Estudo de 1971 & $\begin{array}{c}\text { \% de } \\
\text { Empresas* }\end{array}$ & Estudo de 1996 & $\begin{array}{c}\text { \% de } \\
\text { Empresas }^{\star *}\end{array}$ \\
\hline Fabricação de têxteis & 70,5 & Têxtil/vestuário & 8,1 \\
Fabricação de alimentos & 75,3 & Alimentos/bebidas & 10,7 \\
Fabricação de plásticos & 56,8 & Borracha/plástico & 15,3 \\
\hline
\end{tabular}

* Corresponde ao percentual de empresas que declararam a necessidade de serviços de tradução.

TABELA 4

Análise comparativa do uso de publicações especializadas por setores

\begin{tabular}{lclc}
\hline Estudo de 1971 & $\begin{array}{c}\text { \% de } \\
\text { Empresas }\end{array}$ & Estudo de 1996 & $\begin{array}{c}\% \text { de } \\
\text { Empresas }^{\star *}\end{array}$ \\
\hline Fabricação de têxteis & 53,8 & Têxtil/vestuário & 55,3 \\
Fabricação de alimentos & 44,9 & Alimentos/bebidas & 51,1 \\
Fabricação de plásticos & 56,8 & Borracha/plástico & 62,5
\end{tabular}

* Corresponde ao percentual de empresas que declararam assinar revistas nacionais e estrangeiras.

** Corresponde ao percentual de empresas que declararam ter nas publicações especializadas uma das principais fontes de informação. 
dos assuntos para torná-los minimamente comparáveis entre os dois estudos.

\section{Compatibilização dos assuntos entre os dois estudos:}

1. Processos $=$ tecnologias de processo/produtos/gestão

2. Matérias-primas = matérias-primas/ insumos

3. Controle de qualidade $=$ métodos e técnicas de controle da qualidade

\section{Equipamentos = máquinas/equipa- mentos}

5. Dados econômicos = divulgação de indicadores da atividade econômica

\section{Administração = técnicas modernas de gestão}

7. Planejamento = planejamento e controle da produção

\section{COMENTÁRIOS FINAIS}

Decorridos 25 anos, alterações pouco significativas são observadas no perfil da demanda de informação pelo setor produtivo, quer em relação à demanda em si, quer em relação aos setores industriais demandantes.

Com base nos resultados do seu estudo, o CIT chegou a algumas conclusões sobre os setores pesquisados, bem como sobre os serviços oferecidos à indústria:

- existia uma carência gereralizada de informações;

- todos os assuntos incluídos na questão sobre demandas potenciais interessavam a mais de $50 \%$ das empresas;

- a divulgação de resumos sobre processos, produtividade, equipamento $\mathrm{e}$ novos produtos atendia a mais de $70 \%$ das empresas;

- o serviço de traduções era demandado por $61 \%$ das indústrias e, mesmo considerando a elevada percentagem de técnicos de nível superior nas empresas pesquisadas, colocava-se como imprescindível;

- a demanda de informações era maior
GRÁFICO I

Análise comparativa das demandas potenciais por setores

Gráfico I.A

Têxtil = Têxtil/Vestuário

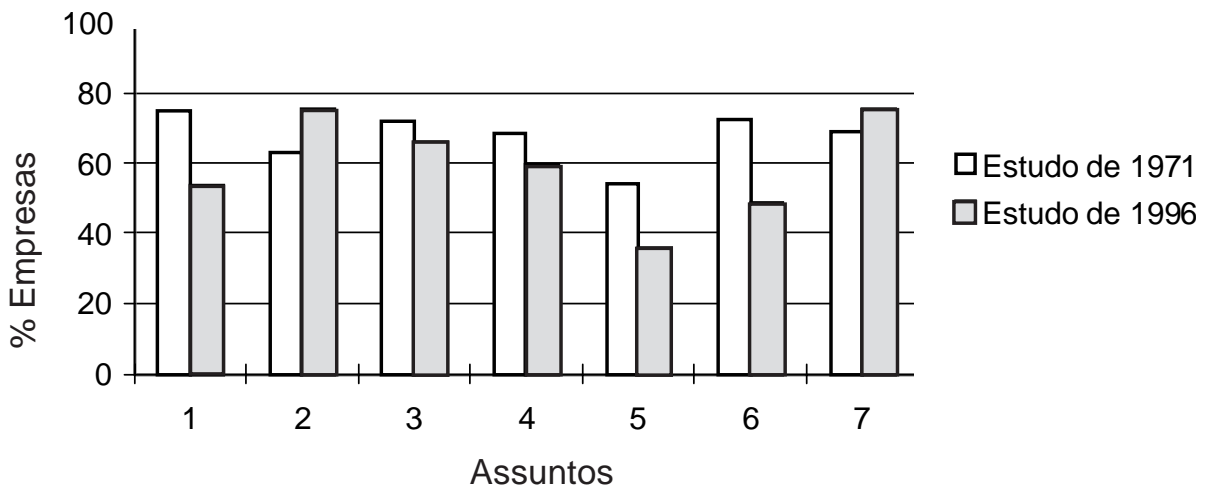

Gráfico I.B

Alimentos = Alimentos $/$ Bebidas

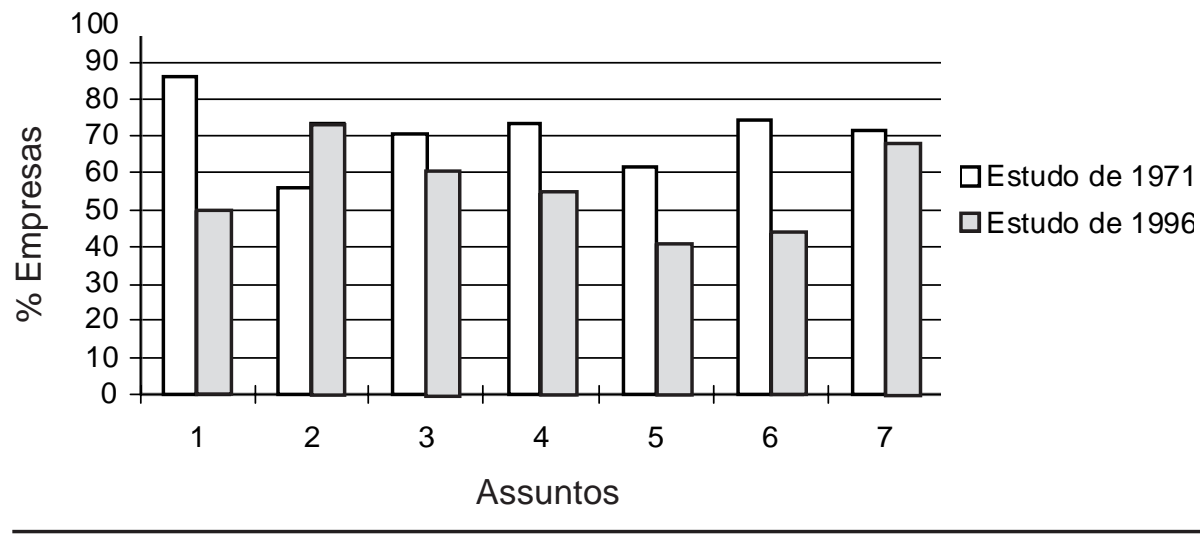

Gráfico I.C

Plástico = Borracha/Plástico

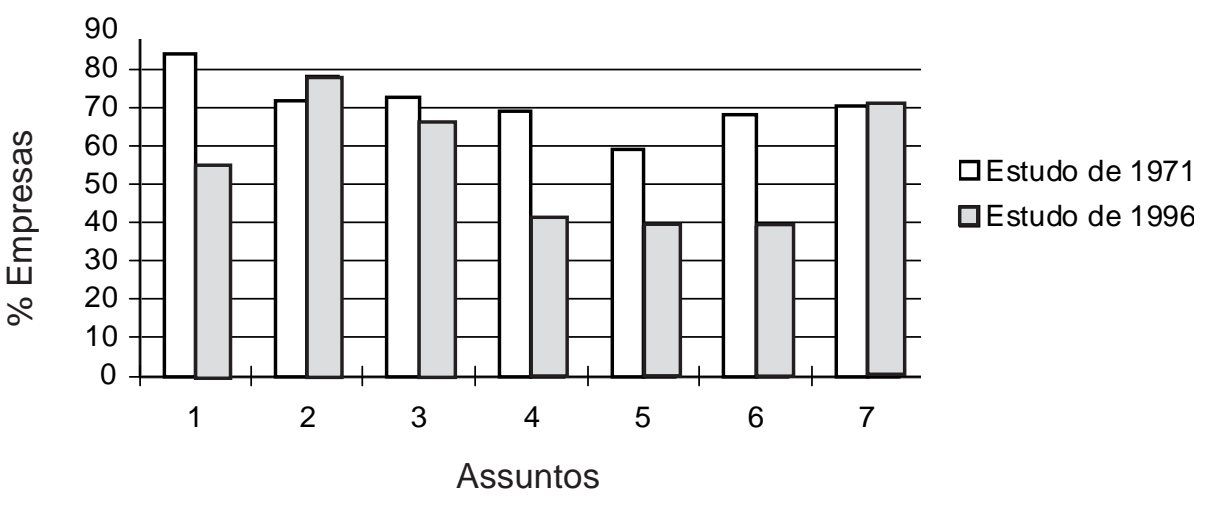


por parte das indústrias que tinham resolvido problemas por intermédio de firmas de consultoria e documentação;

- o pequeno interesse demonstrado pelo item "projetos" indicaria que os setores industriais pesquisados não estavam dando a devida consideração aos incentivos para projetos de expansão industrial e que os órgãos governamentais deveriam ser mais ativos na divulgação desse tipo de informação;

- com exceção do item "novos produtos", os técnicos do CIT tinham sido hábeis ao selecionar os assuntos a serem resumidos e publicados.

Os resultados do estudo da CNI/ Dampi - Senai/Ciet, por sua vez, identificaram tendências de comportamento na amostra pesquisada, com diferenças segundo o porte da empresa.

No segmento das grandes empresas, por exemplo, estão em evidência as que realizam as seguintes atividades:

- consultam maior diversidade de instituições na busca de informação;

- procuram tipos de informação mais variados;

- enfrentam menos dificuldades nessa busca, utilizam mais recursos da própria empresa e publicações especializadas como fontes de informação, bem como dispõem de meios automatizados de organização e acesso à informação.

As pequenas e médias empresas, por sua vez, ora se aproximam, ora se afastam em termos de comportamento:

• na variável "instituições consultadas", por exemplo, as diferenças mais significativas estão nas categoria "institutos de pesquisa e desenvolvimento/universidades" e "órgãos do governo", mais consultadas por médias empresas;

- quanto aos "tipos de informação", a diferença mais significativa ocorre na categoria "transferência de tecnologia/ normas técnicas/propriedade industrial" (19,2\% nas médias e $8,1 \%$ nas pequenas empresas);

- na variável "dificuldades enfrentadas

\section{TABELA 5}

Produtos/serviços de informação que melhor atenderiam às necessidades das empresas consultadas - itens com freqüências mais homogêneas entre os variados portes

Prod./serv. de informação

Oportunidades de negócios/parcerias/...

Realização e divulgação de eventos

Atendimento a consultas técnicas

Tradução de documentos técnicos

Fonte: Demanda por informação..., 1996

na busca por informações", não há diferenças significativas, indicando que médias e pequenas empresas encontram dificuldades similares quando buscam informações;

- entre as "fontes de informação mais utilizadas", as categorias "consultores/ especialistas" e "normas e regulamentos técnicos" são mais usadas pelas médias empresas, que também apresentam maiores freqüências em relação às pequenas empresas quando se consideram as categorias "veículos de acesso às informações automatizados", especialmente "leitoras de CD-ROM" e as "redes de comunicação".

Essas tendências diferenciadas, identificadas por porte da empresa, diminuem para alguns itens, quando se consideram os resultados da última variável do instrumento da pesquisa, que teve como objetivo identificar os "principais produtos/serviços de informação que melhor atenderiam às necessidades das indústrias"26, como se pode observar na tabela 5.

Observa-se, então, que no contexto da globalização da economia, as "oportunidades de negócios/parcerias/joint ventures/terceirização" são os principais produtos/serviços de informação demandados pelas empresas. Por um lado, temos a busca de novos mercados e novos parceiros empresariais, provavelmente para aumentar a competitividade e baixar custos na produção e distribuição de produtos. Este aspecto é reforçado pelo interesse em produtos/serviços sobre "realização e divulgação de eventos", ocasião em que contatos pessoais são realizados e inovações em processos e produtos são apresentados. Com relação ao pro- duto/serviço de informação que parece menos relevante para o setor produtivo na pesquisa de 1996, ou seja, a tradução de documentos técnicos, é provável que os recursos humanos atuando no setor industrial tenham, como exigência do mercado de trabaIho, o conhecimento de idiomas, o que Ihes permite consultar documentos originais.

Novas pesquisas, bem como análises mais aprofundadas dos dados do estudo de 1996, fazem-se necessárias, de modo que os profissionais da informação possam conhecer melhor as demandas específicas dos setores industriais para os quais trabalham. Nesse sentido, será extremamente produtivo que se realizem estudos sobre o uso efetivo da informação, como esse uso se transforma em benefícios nos diversos níveis da organização empresarial e como esse poderoso fator de mudança - o conhecimento - pode ajudar o setor produtivo a vencer os desafios da competitividade na economia global. 


\section{NOTAS E REFERÊNCIAS BIBLIOGRÁFICAS}

1. ARAÚJO, Vânia M.R.H. de. Sistemas de Recuperação da Informação: Nova abordagem teórico-conceitual. Tese apresentada ao Doutorado em Comunicação e Cultura (UFRJ/ECO). Orientadores: Muniz Sodré de Araújo e Gilda Maria Braga. Rio de Janeiro, 1994

O campo do pós-moderno: o saber científico nas sociedades informatizadas. Ciência da Informação v.18, n.1, 1989

3. FREIRE, Isa M. Transferência da informação tecnológica para produtores rurais: Estudo de caso no Rio Grande do Norte. Dissertação apresentada ao Mestrado em Ciência da Informação (CNPq/IBICT . UFRJ). Orientadora: Vânia M.R.H. de Araújo. Rio de Janeiro, 1987, 121p

4. CRONIN, Blaise; TUDOR-SILOVIC, Neva (Ed.). The Knowledge Industries. Levers of economic and social development in the 1990s. Proceedings of an international conference held at the Inter-University Centre for Postgraduate Studies, Dubrovnik, Yugoslavia, 29 May - 3 June 1989. London: Aslib, 1990

5. FREIRE, Isa M. Barreiras na comunicação da informação tecnológica. Ciência da Informação. v.20, n.1, Jan./Jun. 1991

6. LASTRES, Helena M.M. Processo de inovação e Sistemas Nacionais de Inovação. Em: Teorias da Inovação Tecnológica. Especialização em Economia do Petróleo. Rio de Janeiro:Petrobrás:UFRJ, 1994. p. 17

\section{Demand of information by the industrial sector - two studies in a period of 25 years}

\begin{abstract}
As information is increasingly becoming an important input to the production process, more studies about the demand of information by the industrial sector are needed. This paper analyses two studies carried on within a period of 25 years, through the cooperation between the public and private sectors. The similarities and the differences between them are presented, and the main information demanded by the industrial sector revealed by each one are stressed.
\end{abstract}

\section{Keywords}

Information demands; Industrial information; Productive sector.
7. LEMOS, Cristina R. Redes para inovação Estudo de caso de rede regional no Brasil. Dissertação de Mestrado em Ciências em Engenharia de Produção (UFRJ/ COPPE). Orientadora: Helena M.M. Lastres. Rio de Janeiro, 1996, 147p (p.17)

8. BOURDIEU, P. O campo científico. In: ORTIZ, R. (Org.) Pierre Bourdieu. 2ed. São Paulo: Ed. Ática, 1994. Ver também: FREIRE, Isa M. Informação; consciência possível; campo. Um exercício com construtos teóricos. Ciência da Informação, v.24, n.1, jan./abril, 1995

9. WERSiG, G.; NEVELING, U. The phenomena of interest to information science. The Information Scientist. v.9, n.4, p.127-140, 1975, p.128

10. WERSIG, G.; NEVELING, U. Op. cit.

11. BELKIN, N.J.; ROBERTSON, S.E. Information science and the phenomenon of information. Journal of American Society for Information Science, v.27, n.4 p.197-204, 1976

12. WERSIG, G.; NEVELING, U. Op. cit. nota 9

13. ARAÚJO, Vânia M.R.H. de; FREIRE, Isa M. A Rede Internet como canal de comunicação, na perspectiva da Ciência da Informação. Transinformação, v.8, n.2, p.45-55, 1996

14. WERSIG, G. Information science: The study of postmodern knowledge usage. Information Processing \& Management v.29, n.2, p.229-239, 1993. Ver também: WERSIG, G. Information theory. Rede Internet. Busca por autor, 1996

15. FIGUEIREDO, Nice M. de. Estudos de uso e usuários da informação. Brasília: IBICT, 1994, p.7

16. Cf. WERSIG, G. Op. cit. nota 14

17. MUALEM, J.R.V.B. Estudo do atendimento da necessidade de informação industrial do pequeno e médio industrial do Rio de Janeiro pelos órgãos de apoio à pequena e média empresa. Dissertação apresentada ao Mestrado em Ciência da Informação (CNPq/IBICT - UFRJ). Orientadora: Vânia M.R.H. de Araújo. Rio de Janeiro, 1985. 176p

18. BARRETO, A. de A. A transferência de informação, o desenvolvimento tecnológico e a produção de conhecimento. Informare - Cad. Prog. Pós-Grad. Ci. Inf., v.1, n.2, p.2-10, jul./dez. 1995. p.6. De sua pesquisa, Barreto concluiu que "(...) O acesso e uso da informação em ciência e tecnologia foi aceito pela indústria como um dos fatores determinantes do progresso técnico, embora alguns produtos ou serviços de informação possuam maior visibilidade que outros na construção deste progresso".
19. POMPEU, Angela et alii. Levantamento das Necessidades de Informação da Indústria - Um Caso Particular do Brasil. 3ำ Congresso Regional sobre Documentação; II Reunião da FID/CLA, 20/24 setembro 1971, Lima/Peru. Anais. Rio de Janeiro: IBBD, 1972.

20. Confederação Nacional da Indústria/Departamento de Assistência à Média e Pequena Indústria (CNI/Dampi); Serviço Nacional de Aprendizagem Industrial/Centro Internacional para a Educação, Trabalho e Transferência de Tecnologia (Senai/ Ciet). Demanda por Informação Tecnológica pelo Setor Produtivo: Pesquisa 1996. Rio de Janeiro: CNI/Dampi: Senai/ Ciet, 1996.

21. POMPEU, Angela et alii. Op. cit. nota 19. O CIT realizou suas atividades no âmbito do Instituto Nacional de Tecnologia (INT), então vinculado ao Ministério da Indústria e Comércio.

22. CNI/DAMPI; SENAI/CIET. Op. cit. nota 20. Para maiores detalhes, consultar artigo contendo síntese dos resultados da pesquisa, neste mesmo número da Ciência da Informação.

23. Programa de Apoio à Capacitação Tecnológica da Indústria, patrocinado pelo Ministério da Ciência e Tecnologia.

24. Ressalta-se que foram excluídas do estudo avaliações sobre solicitações de dados econômicos, administração, planejamento econômico, produtividade e projetos, temas sob responsabilidade de outra instituição na oferta de informações à indústria.

25. POMPEU, Angela et alii. Op. cit.

26. Os itens completos da tabela para o total das empresas estão disponíveis no artigo com a síntese da pesquisa, neste mesmo número da Ciência da Informação.

\section{Vania M. R. Hermes de Araujo}

Doutora em comunicação e cultura pela Escola de Comunicação da UFRJ. Coordenadora do Núcleo de Informação, SENAI-DN/Centro Internacional para a Educação, Trabalho e Transferência de Tecnologia (Ciet).

\section{Isa Maria Freire}

Doutoranda em ciência da informação e professora/pesquisadora da pós-gradução em ciência da informação, convênio UFRJ-ECO/CNPqIBICT

\section{Teresa Cristina M. Mendes}

Mestre em economia pela PUC/RJ e analista especializada do Núcleo de Tecnologia do Senai-DN/Ciet. 